\title{
Percutaneous Transtracheal Jet Ventilation: An Alternative for Pediatric Difficult Airway Management a Case Report
}

\author{
Parajuli BD ${ }^{1 *}$, Shrestha $\mathrm{PS}^{1}$ and Shrestha $\mathrm{A}^{2}$ \\ ${ }^{1}$ Lecturer, Department of Anaesthesiology, Tribhuvan University Teaching Hospital \\ Maharajgunj, Nepal \\ ${ }^{2}$ Associate Professor, Department of Anaesthesiology, Tribhuvan University Teaching \\ Hospital, Maharajgunj, Nepal.
}

\section{Case Report}

Volume 3 Issue 2

Received Date: July 18, 2018

Published Date: August 03, 2018

*Corresponding author: Bashu Dev Parajuli, Tribhuvan University Teaching Hospital, Maharajgunj, Kathmandu, Nepal, Tel: +977 9851179038; Email: bashuparajuli2012@gmail.com

\begin{abstract}
Airway management is a priority during the conduction of general anaesthesia. Generally, this can be achieved by basic or advanced airway devices. In a minority of cases, these maneuvers fail and a surgical airway is required which can either be surgical cricothyroidectomy following tracheostomy or needle cricothyroidectomy. In paediatric age group, needle cricothyroidectomy following manual jet ventilation is preferred over tracheostomy. Here we described a successful management of airway in a 4 years boy with mouth opening of less than one finger due to burn contracture of face with needle cricothyroidectomy following sander's jet ventilation.
\end{abstract}

Keywords: Manual jet ventilation; Sander's jet ventilation; Paediatric difficult airway

\section{Introduction}

Airway management is a priority during the conduction of general anaesthesia. Generally, this can be achieved by basic or advanced airway devices [1]. Around $85 \%$ of all the mistakes concerning airway management result in irreversible cerebral damage [2] and up to $28 \%$ of all anaesthesia related deaths can be attributed to the mismanagement of difficult airway [3]. The difficult airway represents a complex interaction between patient factors, the clinical setting, and the skills of the practitioner [1]. In cases where conventional methods of airway management fails then surgical airway management is preferred and in emergency condition, needle cricothyroidectomy is the procedure of choice regardless of the age [1]. In pediatric population, needle cricothyroidectomy is preferred than the surgical tracheostomy [4].

\section{Case}

Two years male with a history of flame burn of face and right hand 15 days back, had disfigurement of face and mouth opening of less than 1 finger was planned for release of contracture of angle of mouth Figure 1. Besides, systemic examination and baseline investigations were normal. Consent regarding the modality of airway management (needle cricothyroidectomy or tracheostomy) and possible complications likely to occur due to difficult ventilation and intubation was obtained. 


\section{Anaesthesia \& Critical Care Medicine Journal}

He was fasted for around 6 hours for milk. On day of operation, IV line was secured with 22 G IV cannula in preoperative preparatory room. For aspiration prophylaxis, Metochloropamide and Ranitidine IV were given. Manual jet ventilation (MJV) was connected to the central oxygen supply with gauze pressure reading of 55 psig and the pressure limit in the manual jet ventilator was set at 30 psig. In the $\mathrm{OR}$, preoxygenation was done followed by Pethidine $5 \mathrm{mg}$ and ketamine $10 \mathrm{mg}$. Preserving the spontaneous breath, Inj Lidocaine $2 \% 2 \mathrm{ml}$ was injected over the skin of cricothyroid membrane. Then 14 G IV slightly bent cricothyroidectomy needle was inserted through the cricothyroid membrane by Seldinger technique Figure 2, and he was ventilated with manual jet ventilation (MJV) with rate of $15 / \mathrm{min}$ with aspiratory time of $1 \mathrm{sec}$, followed by pause of $3 \mathrm{sec}$. Adequacy of ventilation was confirmed clinically. $\mathrm{He}$ was then paralyzed with Vecuronium $1 \mathrm{mg}$, since then ventilation was controlled with MJV. Intraoperatively maintenance was done with propofol infusion up to $300 \mathrm{mcg} / \mathrm{kg} / \mathrm{min}$. Release of contracture of the mouth angle was done within 15 mins during which vitals were stable. At the end of surgery, propofol was stopped and muscle relaxation was reversed with neostigmine and atropine. After adequacy of tidal volume(observed clinically), the cricothyroidectomy needle was removed and puncture site was sealed using the surgical tape. There was adequate spontaneous tidal volume (observed in the reservoir bag). Patient was then shifted to ward, where continual monitoring was done. Postoperative period was uneventful and his mouth opening was almost 2 fingers Figure 3.

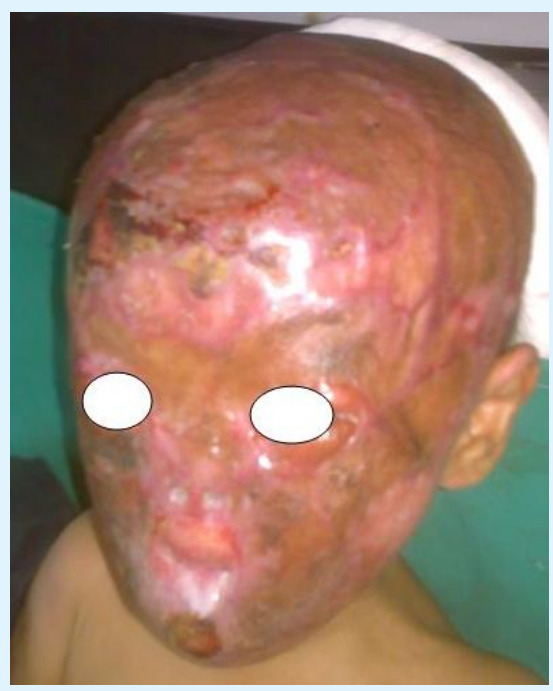

Fig 1: Preoperative picture of the face.
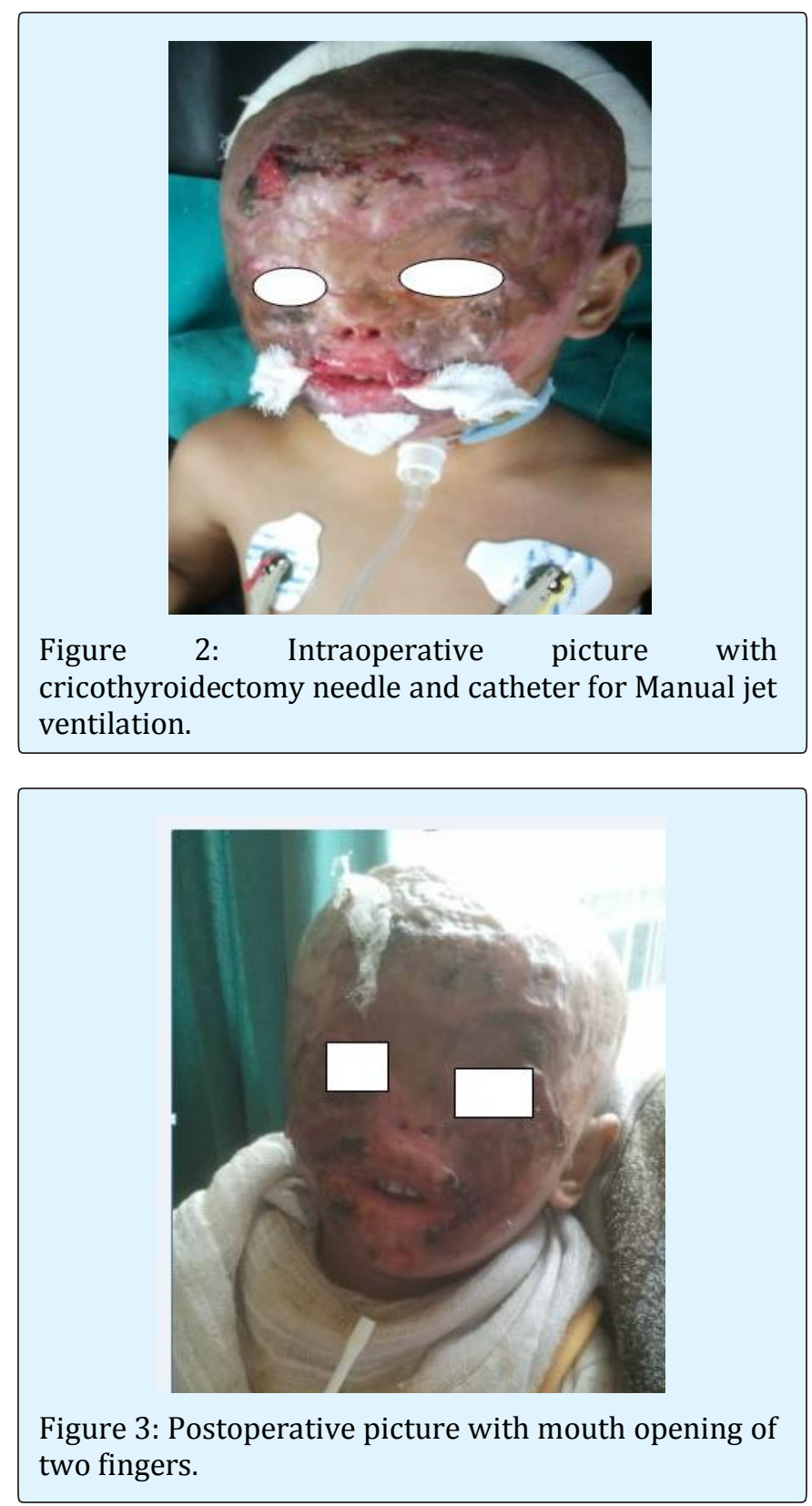

\section{Discussion}

We demonstrate a successful application of percutaneous transtracheal jet ventilation in a case of 4 years boy having mouth opening of one finger due to burn contracture of face. The likely complications that could occur during intubation and morbidity related to tracheostomy could be abandoned with the use of sander's jet ventilation in our case. Sander's jet ventilation or manual jet ventilation was introduced in the year 1967 as a technique of uninterrupted ventilation concurrent 


\section{Anaesthesia \& Critical Care Medicine Journal}

with unhindered surgical access through an open, rigid bronchoscope [5]. Its application was usually limited to short investigate procedures such as laryngoscopy or bronchoscopy. Besides, it has important role in the management of difficult airway [6], failed intubation [7] and "can't intubate, can't ventilate" scenario [8].

The oxygen source is connected to high pressure wall piped oxygen at 55 psig. This is passed through pressure reducing valve and can be further adjusted via a regulator sited near the handset to a pressure that produces the desired chest-wall excursion and maintains oxygenation and adequate gas exchange. Barotrauma is less likely if an initial inflation pressure of less than 4 bars (58 psi) is used [9]. In our case, the pressure regulator was set to 30 psig based on the age of the patient. Short, rigid piping extends from the handset and must fasten securely to the nnkinking cannula, usually by the leur lock connection [10]. In our case, PMO line was connected with nnkinking 14 G cricothyroidectomy cannula, which was sucured with 3-0 me silk suture. In order to minimize complications it is imperative to verify that air can be aspirated from the cannula into a large syringe before the use of high-pressure ventilation [8] which was also done in our case.

A jet ventilation of 8-10 per minute allows adequate time for exhalation via passive recoil of the lung and chest wall and prevents air trapping and build up pressure in small airways [8]. In our case inspiration was allowed for $1 \mathrm{sec}$ then followed by expiratory pause of $3 \mathrm{sec}$ with total ventilation frequency of 15 per minute.

For maintenance during the surgical procedure, total intravenous anaesthesia should be employed [8]. we used propofol infusion at around $300 \mathrm{mcg} / \mathrm{kg} / \mathrm{min}$ for maintenance. Patient should be paralyzed during the manual control of ventilation to avoid the dysynchrony between the jet ventilator and patient [8]. In our case we used veuronium as a paralyzing agent. Other potential complications of manual jet ventilation include kinked cannula, catheter misplacement, haemorrhage at the site insertion, barotrauma, oesophageal injury, surgical emphysema, and gas embolism [8]. No complications were noted in our case. Thus needle cricothyroidectomy for sander's jet ventilation can be a safer option than tracheostomy, especially in the paediatric age group to manage the difficult airway. Following standard technique will reduce the complication.

\section{References}

1. Jeffrey L Apfelbaum, Carin a Hagberg, Robert a Caplan, Casey D. Blitt (2013) Practice guidelines for management of the difficult airway. An updated report by the American Society of Anesthesiologists Task Force on Management of the Difficult Airway. Anesthesiology 118: 251-270.

2. Caplan RA, Posner KL, Ward RJ, Cheney FW (1990) Adverse Respiratory events in Anesthesia: a closed claim analysis. Anesthesiology 72(5): 828-833.

3. Gupta S, Sharma R, Jain D (2005) Airway Assessment: Predictors of Difficult Airway. IJA 49(4): 257-262.

4. Coté CJ, Hartnick CJ (2009) Pediatric transtracheal and cricothyrotomy airway devices for emergency use: Which are appropriate for infants and children? Paediatr Anaesth 19(1): 66-76.

5. Sanders RD (1967) Two ventilating attachments for bronchoscopes. Del Med J 39: 170-75.

6. Mchugh R, Kumar M, Sprung J, Bourke D (2007) Transtracheal jet ventilation in management of the difficult airway. Anaesth Intensive Care 35(3): 406408.

7. Mori M, Fujimoto J, Iwasaki H, Noguchi T (2002) Emergency percutaneous dilational cricothyroidotomy after failed intubation. Anaesth Intensive Care 30(1): 101-102.

8. Evans E, Biro P, Bedforth N (2007) Jet Ventilation. Continuing Education in Anaesthesia. Critical Care \& Pain 7(1): 1-5.

9. Benumof JL, Gaughan SD (1992) Concerns regarding barotrauma during jet ventilation. Anesthesiology 76: 1072-1073.

10. Sdrales L, Benumof JL (1995) Prevention of kinking of a percutaneous transtracheal intravenous catheter. Anesthesiology 82(1): 288-291.

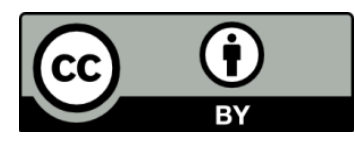

Parajuli BD. Percutaneous Transtracheal Jet Ventilation: An Alternative for Pediatric Difficult Airway Management a Case Report. Anaesth Critic Care Med J 2018, 3(2): 000135. 